\title{
PROBLEMA
}

\section{LA RELEVANCIA DEL DERECHO QUE REMITE A LA MORAL*}

\author{
Juan B. ETCHEVERRY
}

\section{Resumen:}

Puede pensarse que si la obligatoriedad del derecho depende de su corrección moral, la existencia del derecho se vuelve innecesaria, ya que bastaria con la moral para ordenar la vida social. Con este trabajo se busca delinear una propuesta capaz de explicar por qué la existencia del derecho puede continuar siendo relevante, por más que su obligatoriedad dependa en alguna medida de su corrección moral. Para esto último se trabajará sobre la idea de la relevancia de la determinación legal y judicial de las respuestas jurídicas.

\section{Palabras clave:}

Derechos humanos, argumento de la irrelevancia, obligatoriedad, derecho y moral, autoridad, diferencia práctica, legitimidad de origen, determinación jurídica.

* Este trabajo se enmarca en un proyecto de investigación financiado por el Ministerio de Ciencia, Técnica e Innovación Productiva y la Universidad Austral. Versiones previas de este trabajo han sido presentadas en la jornada "La paradoja de la irrelevancia moral del gobierno y del derecho" realizado en junio del 2009 en la Universidad Austral y en el Seminario de Departamento de Filosofia del Derecho de la Universidad de la Coruña llevado a cabo en febrero del 2010. Agradezco los comentarios y las observaciones realizados en dichas oportunidades por los profesores Pedro Serna, Carlos Massini, Juan Cianciardo, Pilar Zambrano, Pedro Rivas, Joaquín Migliore, José Antonio Seoane, Luis Cruz, Oscar Vergara y Carolina Pereira. 


\section{JUAN B. ETCHEVERRY}

\section{Abstract:}

It might be thought that if law's bindingness depends on its moral merit the existence of law turns out to be unnecessary, for morality would be sufficient to organize social life. This article purports to outline an explanation of why the existence of law is still relevant notwithstanding the fact that law's bindingness depends, to some extent, on its moral merit. In arguing this, the author will be focusing on the idea of how relevant are judicial and legal determinacy when solving cases.

\section{Keywords:}

Human Rights, Irrelevance Argument, Bindingness, Law and Morality, Authority, Practical Difference, Original Legitimacy, Legal Determinacy. 
"Luego la ley natural basta para ordenar todas las acciones humanas y, por tanto, no es necesaria una ley humana". ${ }^{1}$

SUMARIO: I. Introducción. II. La paradoja de la irrelevancia moral del derecho. III. Las paradojas de una explicación de la capacidad justificativa del derecho autónoma de la moral. IV. La relevancia de la determinación legal-judicial: una respuesta a la paradoja de la irrelevancia moral del derecho. V. Conclusiones.

\section{INTRODUCCIÓN}

Como puede advertirse en la cita con la que comienza este trabajo (al menos), ya desde el Medioevo hay quienes han argumentado que de existir un orden moral capaz de regular toda la vida social, la existencia del derecho se volvería irrelevante o innecesaria. Los vestigios de este argumento, que perviven hasta la actualidad, ya no ponen en tela de juicio la necesidad de la existencia del derecho. En cambio, suelen presentarse como un modo de cuestionar cualquier tipo de vinculación o relación necesaria entre el derecho y la moral. A partir de este argumento en la actualidad se impugna la idea de que el derecho precisa de la moral para justificar sus decisiones. Más en concreto, se sostiene que si la obligatoriedad del derecho en última instancia depende de su conformidad con la moral el contenido del derecho sería redundante al de la moral. ${ }^{2}$

1 Tomás de Aquino, Summa Theologiae, I-II q. 91, a. 3 (se emplea edición a cargo de P. R. Suarez, Madrid, BAC, 1947). Hay que aclarar que el pasaje citado refleja el modo en que Tomás de Aquino sintetiza una objeción contra su propia visión sobre el lugar que le otorga a la ley natural en la ordenación de la vida social. La respuesta de Tomás de Aquino a esta objeción puede verse principalmente en Ibidem, q. 91 , a. 3 y q 95 , a. 1 y a. 2 .

2 Cfr. Nino, C. S., "La paradoja de la irrelevancia moral del gobierno y el valor epistemológico de la democracia”, en Vigo, R. (coord.), En torno a la democracia, Santa Fe, Rubinzal-Culzoni, p. 98. 
Su aportación en este sentido meramente supone poner de manifiesto el dilema que han de enfrentar quienes defienden que el ordenamiento jurídico se justifica por su conformidad con la moral: o bien las normas jurídicas que lo componen son redundantes de la moral y, en última instancia, superfluas, o bien resultan injustificadas. ${ }^{3}$

El dilema planteado recobra vigencia y su estudio y puesta a prueba se vuelven especialmente interesantes debido a que, en la actualidad, muchas Constituciones parecen receptar criterios morales de validez jurídica. De hecho, hay quienes temen que esta explícita vinculación entre el derecho y la moral termine minando el poder o la capacidad de gobierno de las leyes (delegando tal función en última instancia en los jueces).

Como se verá a continuación, existen muchas formas de enunciar este argumento. Sin embargo, lo que tienen en común estas diferentes formulaciones es que buscan criticar las teorias que vinculan la validez, obligatoriedad y capacidad justificativa del derecho con la moral.

Con este trabajo se busca explorar la posibilidad de superar el dilema planteado por este argumento. Con esta finalidad, en primer lugar se expondrán los diferentes modos en que ha sido enunciado a lo largo de la historia. Junto con esta exposición se advertirán algunas dificultades de defender la corrección de este argumento a fin de explicar la obligatoriedad y capacidad justificativa del derecho de una forma completamente autónoma de la moral. La exposición de dichas dificultades ayudará a poner de manifiesto las limitaciones de algunos puntos de vista o perspectivas desde los que se estudian estos temas. ${ }^{4}$

A fin de de superar el dilema presentado se ofrecerá una explicación del papel del derecho y la moral en la regulación

3 Cfr. Raz, J., Practical Reason and Norms, Londres, Hutchinson, 1978, trad. de J. Ruiz Manero, Razón Práctica y Normas, Madrid, Centro de Estudios Constitucionales, 1991, p. 242.

4 Sobre las dificultades de algunos modos de aproximarse al estudio del Derecho cfr. Etcheverry, J. B., "Cuestiones metodológicas que la analytical jurisprudence actual todavia no ha resuelto", Ideas y Derecho 8, 2008, pp. 167-187. 
de la vida social que reconoce la relevancia de las determinaciones legales y judiciales concretas. La importancia de dichas determinaciones radicaría en su capacidad para prevenir y resolver conflictos jurídicos y coordinar la conducta de sus destinatarios de forma racional.

En último término, se aspira a que esta explicación ayude a responder las preguntas centrales que subyacen a los temas que se abordarán en este trabajo: ¿la obligatoriedad del derecho en última instancia depende de algún tipo de conformidad con la moral? De ser asi, ¿es necesaria la existencia del derecho? y ¿por qué regirnos por el derecho y no, más bien, sólo por la moral?

\section{LA PARADOJA DE LA IRRELEVANCIA MORAL DEL DERECHO}

Como se ha anticipado, el dilema planteado puede ser presentado de diversas formas. El destacado profesor argentino Carlos Santiago Nino ha advertido al menos tres de estas formas: "la paradoja de la irrelevancia moral del gobierno, del derecho (en general) y (más en concreto) de la Constitución".

A continuación se expondrán éstas y otras formas en las que se ha enunciado la denominada paradoja de la irrelevancia moral del derecho.

\section{Irrelevancia moral del derecho o limitación en su función de guía}

Un modo de presentar la paradoja de la irrelevancia moral del derecho pone en tela de juicio la capacidad de las normas jurídicas para guiar las conductas si la validez, y en última instancia, la obligatoriedad de dichas normas depende de su corrección moral.

Esta versión de la paradoja, en último término, se basa en la idea de que las personas, o bien siguen a las normas jurídicas, o bien actúan moralmente, pero no pueden ser guiadas a la vez por la moral y por el derecho. Esto se debe- 
ría a que si las personas hacen lo que dice una norma jurídica pero sólo después de pensar moralmente, estas personas no serian realmente guiadas por dicha norma jurídica sino únicamente por la moral. En cambio, si hacen lo que dice la norma jurídica sin hacer un balance de razones - entre las que se incluirian las morales-, entonces no actuarian moralmente. ${ }^{5}$

Esto conduce a que algunos autores defiendan que el único modo de escapar a este dilema y explicar cómo las reglas guían las conductas es por medio de un modelo de toma decisiones que llaman "limitado". Para Shapiro, dicho modelo sugiere que los seres humanos pueden interiorizar las reglas de forma tal que les permite hacer cosas que los escrúpulos morales no les permitirian. Desde que existen razones morales poderosas para interiorizar las reglas, y que las personas que interiorizan reglas no sean responsables de su cumplimiento sin restricciones, se podría obrar conforme a las reglas y moralmente. Por otra parte, este modelo de toma de decisiones sería el que mejor explica el aspecto de las reglas que tiene que ver con su capacidad para cerrar posibilidades futuras que resulten inconsistentes con ellas. ${ }^{6}$

Toda esta elaboración acerca del papel de las reglas en el razonamiento práctico permite que algunos autores sostengan que las normas que remiten a criterios valorativos de validez jurídica generan que las normas supuestamente aceptadas como válidas por dichos criterios se vuelvan superfluas o incapaces de guiar las conductas. ${ }^{7}$

Las normas válidas en virtud de su contenido moral serían incapaces de cumplir con la función de guía que tiene

5 Cfr. Shapiro, S., "Judicial Can't”, en Villanueva, E. (ed.), Legal and Political Philosophy, Amsterdam-Nueva York, Rodopi, 2002, pp. 182 y 193.

6 Cfr. Shapiro, S. J., "The Difference That Rules Make", en Bix, B., (ed.), Analyzing Law: New Essays in Legal Theory, Oxford, Clarendon Press, 1998, p. 47.

7 En concreto, Shapiro afirma que "una vez que un agente está motivado a obrar siguiendo la parte incluyente de una regla de reconocimiento y entiende cómo aplicarla, las reglas primarias que están pretendidamente validadas por esa parte de la regla [de reconocimiento] no pueden generar una diferencia práctica”, Ibidem, p. 58. 
el derecho, por un lado, porque exigen a quienes han de obedecerlas deliberar sobre los méritos de seguirla. Esto supondria que, en realidad, en estos casos las obligaciones no son aprendidas de las normas jurídicas sino directamente de la moral. Dicho de otro modo, se cree que este tipo de normas le dice a los individuos que deben actuar según las reglas que los obligan, lo que sería como no decirles nada. ${ }^{8}$ Casualmente, se cree que quien tiene la función de dictar normas debería eliminar los problemas asociados con las necesidades de las personas de distinguir por sí mismas entre las normas legitimas y las ilegitimas. Por esto, las normas que sólo pueden ser identificadas acudiendo a las mismas preguntas que dichas normas supuestamente resuelven, no tendrian utilidad alguna y serian incapaz de cumplir con sus funciones epistémicas. ${ }^{9}$

Por otra parte, las reglas cuya validez depende de criterios valorativos no sólo no permitirian que se aprendan de ellas las obligaciones jurídicas, sino que tampoco lograrian motivar realmente la acción. En otras palabras, dichas reglas no lograrian por sí mismas que se crea en la legitimidad de sus estándares de conducta. ${ }^{10}$ La creencia en la legitimidad de sus estándares de conducta en realidad derivaría de los criterios valorativos de los que depende su validez jurídica. ${ }^{11}$

8 Cfr. Sespera, S. J., "On Hart's Way Out", en Coleman, J., (ed.), Hart's Postscript: Essays on the Postscript to the Concept of Law, Oxford, Oxford University Press, 2001, p. 177.

9 Ibidem, pp. 184 y 185.

10 Ibidem, p. 173.

11 Idem. Para Shapiro la tesis de Hart sobre la función de guía del Derecho está compuesta por dos afirmaciones: "la función primordial del Derecho es guiar epistémicamente la conducta de los ciudadanos ordinarios por medio de las reglas primarias y guiar por motivación la conducta de los funcionarios jurídicos por medio de las reglas secundarias". Ibidem, p. 175. De todo lo expuesto Shapiro concluye que la adopción por parte de Hart de un positivismo soft o incluyente a fin de superar las críticas que su versión del positivismo jurídico sufrió por parte de Dworkin, resulta incoherente con su concepción del Derecho según la cual toda regla tiene la función de guiar conductas, pues para esto debe poder hacer una diferencia práctica. Cfr. ibidem, p. 189. 


\section{Irrelevancia moral del derecho o pérdida de autoridad}

Un segundo ejemplo de cómo puede enunciarse la paradoja de la irrelevancia moral del derecho cuestiona el sentido en que se afirma que un individuo, órgano o gobierno, tiene autoridad si la obligatoriedad de sus decisiones en última instancia depende de que sean moralmente correctas. Lo que se cuestiona es la capacidad de una autoridad para aportar razones para la acción capaces de hacer una diferencia en el razonamiento práctico de quienes están a su cargo si en última instancia la obediencia a sus decisiones depende de que estas últimas sean moralmente correctas.

Uno de los autores que ha realizado grandes esfuerzos por explicar el papel de la autoridad evitando caer en la paradoja en cuestión es Joseph Raz. La autoridad, para Raz, depende de que por lo menos algunas de las órdenes o instrucciones autoritativas de una persona sean consideradas por otras personas como razones para realizar un acto, junto con una razón excluyente para no abstenerse de actuar si tales razones entran en conflicto con otras razones. Así, tener autoridad implicaría tener un poder para ordenar y dar instrucciones, pudiendo crear de ese modo una nueva razón operativa, que estaría configurada con una razón excluyente. ${ }^{12}$

A modo de resumen de su explicación de la autoridad, Raz propone tres tesis: la "tesis de la dependencia", la "tesis de la justificación normal" y la "tesis del reemplazo" (pre-emption thesis). La "tesis de la dependencia" afirma que las directivas autoritativas deben basarse, entre otros factores, en razones que se apliquen a los destinatarios de esas directivas y que afecten a las circunstancias que la directiva cubre. Estas razones son denominadas por Raz "razones

12 Cfr. Raz, J., Practical Reason and Norms, Londres, Hutchinson, 1975, trad. de J. Ruiz Manero, Razón práctica y normas, Madrid, Centro de Estudios Constitucionales, 1991, pp. 44-47 y 70-71. Hemos tratado esta cuestión en Etcheverry, J. B., El debate sobre el positivismo juridico incluyente. Un estado de la cuestión, México, UNAM, 2006, pp. 32 y ss. 
dependientes". ${ }^{13}$ Esta tesis no significa que la autoridad deba mandar de acuerdo a los intereses de los súbditos, ni que las directivas deban reflejar estas razones para ser obligatorias. La "tesis de la dependencia" se comprende mejor junto con las restantes tesis que presenta Raz. Para la "tesis de la justificación normal" el destinatario probablemente cumplirá mejor con las razones que se le aplican si acepta las órdenes de la autoridad como obligatorias y autoritativas, e intenta cumplirlas, que si trata de seguir las razones que se le aplican en forma directa. ${ }^{14}$ Esto podria ser así, por ejemplo, por la especial competencia de la autoridad o porque sólo siguiendo las instrucciones de una autoridad podría asegurarse una coordinación de quienes están a su cargo. Por último, según la "tesis del reemplazo", "el hecho de que una autoridad exija el cumplimiento de una acción constituye una razón para su cumplimiento que no debe agregarse a todas las demás razones relevantes al momento de evaluar qué hacer, sino que debe reemplazar a algunas de ellas". ${ }^{15}$

De estas tres tesis, Raz deriva la concepción de la autoridad como servicio. Según esta concepción, la autoridad está para servir al sujeto, aunque no siempre coincida con su interés. Por eso, las reglas y directivas con autoridad son razones para la acción con independencia de su contenido. ${ }^{16}$

A fin de ilustrar estas afirmaciones, Raz ofrece un ejemplo en el que dos personas presentan su controversia ante un árbitro. Éste tiene autoridad para resolver la disputa, porque ambos han decidido respetar su decisión. ${ }^{17}$ De este

13 Raz, J., Ethics in the Public Domain, Oxford, Clarendon Press, 1994, trad. de M. L. Melón, La ética en el ámbito público, Barcelona, Gedisa, 2001, p. 231. Si bien se cita la traducción al castellano de esta obra, siempre se trabaja con el texto original a la vista.

14 Ibidem, p. 231.

15 Idem.

16 Cfr. Raz, J., The Morality of Freedom, Oxford, Clarendon Press, 1988 (reimp. 2001), pp. 56-59.

17 Cfr. Raz, J., La ética en el ámbito público, cit., p. 229. 
hecho, Raz destaca dos características. En primer lugar, el laudo arbitral constituye una razón dependiente para la acción de los litigantes, aunque no es simplemente una razón que se agrega a otras, por medio de las cuales los litigantes resolverán lo que consideran razonable. ${ }^{18}$ En segundo lugar, la decisión arbitral debe reemplazar las razones de las cuales depende debido a que las partes deciden seguir el juicio del árbitro sobre sus balances de razones al comprometerse a obedecer su decisión. En síntesis, se considera que el laudo se comporta como una razón reemplazante (pre-emptive reason) al desplazar a las demás razones para obrar. ${ }^{19}$

A partir de este ejemplo, Raz observa que los rasgos de dependencia y reemplazo se encuentran intimamente vinculados. Debido a que el árbitro debe decidir con base en unas razones, los litigantes no deben basarse en ellas posteriormente. Dado que las partes le entregan al árbitro la tarea de evaluar esas razones, si las partes no rechazan esas razones como posibles bases de su obrar contradirian el objeto mismo del arbitraje. Por esto, a juicio del profesor de Oxford, "la única manera correcta de reconocer la autoridad del árbitro es tomarla como una razón para la acción que reemplaza las razones sobre las cuales éste debió basarse para su decisión".20

En síntesis, visiones como la de Raz sostienen que alguien tiene autoridad sólo cuando sus instrucciones u órdenes son consideradas por otros como razones para realizar un acto y para excluir el balance de razones que, de no tener tales instrucciones u órdenes, realizarian. Así, las razones que aporta la autoridad con sus instrucciones y órde-

18 Ibidem, p. 230.

19 Aclara Raz que si bien el laudo es una razón reemplazante, esto no significa que sea una razón absoluta. Es decir, que deba ser obedecida pase lo que pase. Para Raz es posible apelar esta decisión y hasta desobedecerla en determinadas circunstancias. Por ejemplo, si el árbitro estuviera alcoholizado al decidir el caso, o si hubiese sido sobornado. Así, lo que quiere decirse con razón reemplazante es que las razones en las que podrian haberse basado las partes para justificar su acción antes del laudo no pueden alegarse después de que éste haya sido emitido. Idem.

20 Idem. 
nes reemplazarian las razones de quienes están bajo dicha autoridad. Dicho de otra manera, la obligatoriedad de una decisión de la autoridad no puede depender de su corrección moral, porque entonces no lograría ni excluir el balance de razones de sus receptores ni reemplazar las razones que surjan de dicho balance y, por lo tanto, perdería su carácter "autoritativo".

\section{Irrelevancia moral de la Constitución o superfluidad de su capacidad para asignar validez a otras normas}

Un ejemplo interesante de cómo ha sido presentada la paradoja de la irrelevancia moral del derecho está vinculado con el debate desatado en el derecho constitucional acerca del papel o rol que tienen los valores o principios que son incorporados en los sistemas constitucionales actuales y que buscan reconocer derechos que suelen presentarse como indiscutibles e irrenunciables. En este sentido, una de las preguntas que ha de responder el derecho constitucional es la siguiente: ¿por qué hemos de aceptar el contenido de las Constituciones como válido u obligatorio y capaz de asignar validez a otras reglas? Esta pregunta sobre la legitimidad del contenido de las Constituciones actuales últimamente ha sido reformulada del siguiente modo: ¿por qué hemos de aceptar que las Constituciones (algunas de ellas surgidas hace mucho tiempo y sin la participación de importantes segmentos de la población) establezcan "cotos vedados" a la discusión pública y democrática? ${ }^{21}$

Dado que las Constituciones no pueden adscribirse validez a sí mismas, éstas han de recurrir a elementos externos a ellas para justificar su carácter obligatorio y el de las normas jurídicas a las que les asignan validez. La dificultad de fundar la legitimidad de las Constituciones meramente en la virtud intelectual de sus redactores, vuelve razonable intentar responder el intringulis apelando al "acierto" o la

21 Gargarella, R., "La Constitución de la democracia deliberativa según Carlos Nino", Revista Jurídica de la Universidad de Palermo, 3, 1998, p. 195. 
"bondad" del contenido de sus textos. Aquí es donde surgirian nuevamente las dificultades advertidas por la paradoja de la irrelevancia moral de derecho. En este caso se pone en duda la importancia de los órdenes constitucionales para asignar validez al resto del ordenamiento jurídico, si dichos órdenes a su vez necesitan ser justificados por su contenido moralmente "correcto".

Dicho de otro modo, si la legitimidad de una Constitución, que le permite asignar validez a otras reglas y decisiones jurídicas, se basa en la corrección moral de sus contenidos (que reconocen algunos derechos fundamentales que pueden ser inferidos directamente de la moral), entonces las Constituciones no son en última instancia las que justifican la obligatoriedad de las reglas infra-constitucionales y de las decisiones jurídicas. En este sentido, podría decirse que los contenidos de las Constituciones que permiten justificar la validez de las reglas infra-constitucionales y de las decisiones jurídicas resultan redundantes (y, por lo tanto, superfluos) con respecto a los contenidos de la moral considerados valiosos antes de su incorporación en los textos constitucionales. ${ }^{22}$

\section{Irrelevancia moral de la Constitución o superfluidad de las normas infra-constitucionales}

Otro modo de presentar la paradoja de la irrelevancia moral del Derecho vinculado con la disputa sobre el lugar que ocupan los principios a los que hacen referencia los sistemas constitucionales actuales pone en duda la relevancia de las normas infra-constitucionales.

Al respecto, una manera de entender el efecto de irradiación (Ausstrahlungswirkung), que generan los principios constitucionales sobre el resto del ordenamiento jurídico supone que su presencia no sólo se vuelve inevitable en

22 Cfr. Nino, C. S., The Constitution of Deliberative Democracy, New Haven, Yale University Press, 1996, trad. de R. P. Saba, La Constitución de la democracia deliberativa, Barcelona, Gedisa, 1997, pp. 42-46. 
todo acto de creación y de adjudicación del derecho, sino que en realidad toda respuesta o solución jurídica deba buscarse y encontrarse en la Constitución y no en las normas infra-constitucionales que a lo sumo serán redundantes y, por lo tanto, irrelevantes.

De algún modo, entender de esta manera el papel que tienen los principios constitucionales pasa del dogmatismo que presume la racionalidad del legislador a un dogmatismo que defiende que todo lo que es estipulado por el constituyente es justo, coherente, completo, inmejorable o no necesitado de ser determinado.

Como crítica a la constitucionalización material que se advierte en la mayoría de los sistemas y prácticas constitucionales (al menos, de occidente) ha surgido un argumento vinculado con lo que acaba de exponerse. En concreto, dicho argumento presenta como riesgoso que las Constituciones incorporen derechos fundamentales expresados como principios, que gocen de la máxima jerarquía jurídica, que resulten directamente aplicables, que tienden a su optimización y que por su amplitud o generalidad pudiesen ser capaces de contener todo el ordenamiento jurídico. A esta posibilidad se le critica porque la necesidad de concretización creativa que tienen dichos principios y su potencial conflictividad terminaría desplazando al legislador de su competencia originaria de creación del derecho y otorgándosela a los tribunales con jurisdicción constitucional. ${ }^{23}$

En palabras de Böckenförde,

23 Cfr. Böckenförde, E. W., "Sobre la situación de la dogmática de los derechos fundamentales tras 40 años de Ley Fundamental", Escritos sobre Derechos fundamentales, trad. De J. L. Requejo Pagés y I. Villaverde Menéndez, Nomos, Baden-Baden, 1993, pp. 125 y ss., y Alexy, R., Tres escritos sobre los derechos fundamentales y la teoría de los principios, trad. De C. Bernal Pulido, Bogotá, Universidad Externado de Colombia, 2003, pp. 50 y ss., y El concepto y la validez del derecho, Barcelona, Gedisa, pp. 160 y ss. Hemos advertido algunos riesgos de un sistema jurídico sobre-constitucionalizado en Etcheverry, J. B., "Building a Democracy respectful of Human Rights. The Constitutional Design that Emerges from the Philosophical Roots of the Constitution of Timor-Leste", en Binchy, W. (ed.), Timor-Leste Constitution, Dublin, Clarus, 2010, pp. y 18 ss. (en prensa). 
...si la Constitución se limita a establecer un marco, al Tribunal que tiene que garantizar la Constitución le está vedada por principio la intervención en el proceso de llenado de dicho marco, especialmente la determinación de las posiciones jurídica singulares. Si la Constitución es orden jurídico fundamental de la comunidad, si tiene una función dirigente universal, entonces es también función del Tribunal Constitucional la determinación de las posiciones jurídicas singulares, en la medida en que se trate de contenidos jurídicos sustanciales; dado que los pre-establecidos constitucionales son indeterminados, el Tribunal Constitucional se convierte, en su labor de concretización de su alcance, de modo específico, en el señor de la Constitución. ${ }^{24}$

\section{Irrelevancia moral del derecho o depreciación del factor "legitimidad de origen"}

Por último, otro ejemplo de cómo puede presentarse el argumento de la "irrelevancia moral del derecho" está vinculado con el debate sobre la diferente capacidad justificadora que tienen las decisiones tomadas por los gobiernos legitimos con respecto a las decisiones tomadas por gobiernos que detentan el poder de forma ilegitima. La pregunta en torno a esta cuestión seria: ¿hace alguna diferencia respecto de las normas juridicas el hecho de que ellas surjan de un gobierno legítimo?25 $\mathrm{Si}$ el orden jurídico y la autoridad de quienes emiten directivas generales se justifican por su capacidad de promover el respeto de los derechos humanos, la corrección moral de sus decisiones, etcétera; en la medida que las normas jurídicas y las decisiones autoritativas logren estos objetivos poco importa la forma del gobierno que las dicte. Así, si alguien usurpase el poder pero lo usase para dictar normas que cumplen con las exigencias de la

24 Böckenförde, E. W., "Sobre la situación de la dogmática de los derechos fundamentales tras 40 años de Ley Fundamental", cit., p. 137.

25 Cfr. Nino, C. S., "La paradoja de la irrelevancia moral del gobierno y el valor epistemológico de la democracia”, cit., p. 98. 
moral, podría pensarse que nada se le podría objetar. Más aún, si las normas sancionadas por el usurpador son necesarias para que se satisfagan las exigencias de la moral, podría concluirse que aquellas normas están justificadas. ${ }^{26}$

\section{LAS PARADOJAS DE UNA EXPLICACIÓN DE LA CAPACIDAD JUSTIFICATIVA DEL DERECHO AUTÓNOMA DE LA MORAL}

La paradoja de la irrelevancia moral del derecho resulta fácilmente superable si se niega, al menos como hipótesis general, que la justificación del derecho dependa de su corrección moral. De hecho, muchas veces esta paradoja es presentada como argumento para rechazar toda explicación que no conciba a la capacidad justificativa del derecho como completamente autónoma de la moral.

Para defender una posición como ésta, muchas veces se advierte que es un hecho dificilmente refutable que en muchas ocasiones algunas personas son indiferentes frente a los reclamos de la moral. Más aún, hay quienes consideran que esto último es así en última instancia no por rechazo o desidia de los individuos para obrar conforme a la moral, sino porque no saben o conocen los principios morales necesarios para juzgar el comportamiento propio y ajeno. Justamente, por lo anterior puede pensarse que las autoridades y las normas jurídicas serían quienes deben fijar dichos criterios de comportamiento.

A continuación se pondrán de manifiesto al menos tres paradojas nuevas que deben enfrentar quienes pretenden resolver la paradoja de la irrelevancia moral del derecho explicando la capacidad justificativa del derecho como completamente autónoma a la moral.

26 Cfr. Nino, C. S., Ética y derechos humanos. Un ensayo de fundamentación, Barcelona, Ariel, 1989, pp. 369 y 370. 


\section{La paradoja de la indiferencia o la ignorancia de la moral}

La primera dificultad que han de enfrentar quienes defienden una explicación de la capacidad justificativa del derecho completamente independiente de criterios morales es que este tipo de explicación paradójicamente resulta insuficiente para superar o resolver en última instancia el problema planteado por la paradoja de la irrelevancia. Como advierte Nino, todo intento de explicar la capacidad justificativa del derecho de forma completamente autónoma de la moral fracasa porque el derecho no puede justificar su obligatoriedad por sí mismo. ${ }^{27}$

En este sentido, meramente describir que las normas jurídicas expresan que ciertas conductas son obligatorias no alcanza para explicar por qué es obligatorio o justificado obrar lo que ellas expresan. Como ejemplifica Alexy, "partiendo sólo de: Pedro me ha dicho: "Estás obligado a darme 100DM", no se infiere: Estoy obligado a darle 100DM".28

Por otro parte, como explica - entre otros- Kelsen, sugerir que las normas jurídicas son obligatorias porque son eficaces tiene la dificultad para explicar cómo se pasa de un hecho (que las normas jurídicas son de hecho obedecidas) a su justificación normativa (que existen razones para obedecer dichas normas). ${ }^{29}$ Como es sabido, para este autor "que una norma [...] valga significa que obliga". ${ }^{30}$ Por todo esto, sostiene que "el fundamento de validez de una norma [de su obligatoriedad para el sistema jurídico] sólo puede encontrarse en la validez de otra norma". ${ }^{31}$ De hecho, los sistemas jurídicos actuales suelen tener normas jurídicas (v. g., en sus Constituciones) que establecen criterios de validez aplicables al resto de las normas jurídicas. Sin embargo,

27 Cfr. Nino, C. S., "La paradoja de la irrelevancia moral del gobierno y el valor epistemológico de la democracia", cit., pp. 97 y ss.

28 Alexy, R., El concepto y la validez del derecho, cit., p. 102.

29 Cfr. Kelsen, H., Reine Rechtslehre, 2a. ed., Viena, 1960, trad. de Vernengo, R., Teoría pura del derecho, México, Porrúa, 1998, p. 201.

30 Idem.

31 Idem. 
resta todavía explicar la validez de las normas que intervienen en la fundamentación de la validez de las otras normas. Debido a que este proceso no puede continuarse al infinito, Kelsen apela a la idea de la "norma fundante básica" (Grundnorm) que permitiría dotar de validez al resto del ordenamiento jurídico. No menores son las dificultades de esta norma fundante para explicar por qué es obligatorio obrar lo que mandan las normas validadas por ella. Si bien, parece "posible", como sugiere Kelsen, presuponer esta norma fundante e incluso puede ser "necesario" esto si se quiere hablar de validez jurídica; 32 no obstante, esto no alcanzaría para explicar la obligatoriedad de la norma fundante (que para Kelsen no puede ser fundamentada) y la del resto del ordenamiento jurídico cuya validez depende de ella. ${ }^{33}$

Una de las alternativas más importantes a la explicación de la validez del derecho ofrecida por la norma fundante de Kelsen, ha sido propuesta por la "regla de reconocimiento" (rule of recognition) de Hart. Como es sabido, la regla de reconocimiento es la regla secundaria (regla sobre reglas) que suministra los criterios para la identificación del derecho válido y su existencia se puede advertir en la manera en que el resto de las reglas son identificadas como válidas por los tribunales. La principal diferencia con la norma fundante es que la explicación que ofrece la regla de reconocimiento expresamente pone énfasis en el carácter esencialmente fáctico de los enunciados de validez hechos por los operadores jurídicos que la conforman sin, por ello, identificar validez con eficacia. Así, la regla de reconocimiento no es considerada válida o inválida, sino que su existencia y contenido sería una cuestión de hecho. ${ }^{34}$

El interesante paso dado por Hart al vincular los criterios de validez de las reglas con el modo en que de hecho son

32 Ibidem, pp. 204 y ss.

33 Cfr. Ross, A., On Law and Justice, London, Stevens, 1958, pp. 17 y ss.

34 Cfr. Hart, H. L. A., The Concept of Law, Oxford, Clarendon Press, 1961, trad. de G. Carrió, El concepto de derecho, Buenos Aires, Abeledo Perrot, 1963, pp. 136 y 137. 
identificadas como parte del sistema jurídico, responde a la perspectiva interna (es decir, el punto de vista de quienes usan las reglas como criterios para valorar su conducta y la de los demás) que adopta para describir el derecho. Sin embargo, esta propuesta descriptiva resulta limitada porque tampoco logra explicar por qué (desde la perspectiva del que ha de obedecer o aplicar las reglas jurídicas) obliga la regla de reconocimiento (o el resto de las normas), ya que de la existencia de una práctica que acepta unos criterios como aquellos que permiten identificar el derecho válido no se infiere la obligatoriedad de comportarse de acuerdo con esta práctica. 35

Todo esto pone de manifiesto que pareciera que en última instancia el único modo en que el derecho puede justificar su obligatoriedad es apelando a algunos principios morales últimos (supra-legales), válidos por su mérito y no justificables a su vez por otros principios. ${ }^{36}$ Esto supone, como advierte Alexy, que el discurso jurídico termina siendo un caso especial del discurso moral. ${ }^{37}$

Por esto, como sugiere Nino, cuando un juez invoca una norma para justificar su decisión, no se refiere a esa norma como práctica social observable como un hecho desde el punto de vista externo, sino que se refiere a ésta desde el punto de vista interno como si fuese una proposición normativa o moral. 38

A modo de conclusión, debido a que: (i) el planteo de la paradoja de la irrelevancia moral del derecho tiene interés para quienes se preocupan por explicar la capacidad justificativa del derecho; y (ii) como se ha visto, sólo es posible explicar esto apelando a unos principios morales últimos, no justificables por otros principios; (iii) si se considera que tales principios no existen, no son susceptibles de ser cono-

35 Cfr. Alexy, R., El concepto y la validez del derecho, cit., p. 122.

36 Cfr. Bayón, J. C., La normatividad del Derecho. Deber jurídico y razones para la acción, Madrid, Centro de Estudios Constitucionales, 1991, pp. 729 y ss.

37 Cfr. Alexy, R., Teoría de la argumentación jurídica, trad. de M. Atienza y I. Espejo, Madrid, Centro de Estudios Constitucionales, 1989, pp. 206 y ss.

38 Nino, C. S., La Constitución de la democracia deliberativa, cit., p. 44. 
cidos, son relativos, no son tenidos en cuenta y, por lo tanto, se intenta justificar al derecho de modo autónomo a la moral; entonces (iv) pierde todo sentido preguntarnos por la justificación del derecho y adentrarnos en el punto de vista desde el que se está planteando el problema de la paradoja: el del hombre moral que guía su conducta (y critica la ajena) por principios morales. ${ }^{39}$ Por todo esto, quienes apoyándose en la paradoja de la irrelevancia moral del derecho sostienen que la justificación del derecho no depende o ha de depender de la moral paradójicamente se ven obligados a abandonar, en último término, toda posibilidad de explicación de la justificación del derecho y, por lo tanto, de resolución del dilema planteado por la paradoja en cuestión.

\section{La paradoja de la incapacidad radical del derecho actual para guiar, obligar o resultar autoritativo}

La segunda paradoja que han de enfrentar las posiciones que a partir de la paradoja de la irrelevancia moral del derecho sostienen que para que el derecho logre resultar autoritativo o capaz de guiar su validez u obligatoriedad ha de ser independiente del razonamiento moral, es su carácter contra-fáctico. Dichos esfuerzos no advierten que lo que defienden supone afirmar que el derecho actual (que expresamente incorpora criterios morales de validez jurídica) se ha vuelto incapaz de obligar, guiar y, por tanto, resultar autoritativo.

Hoy en día resulta dificil no advertir las constantes referencias que hace el derecho a criterios valorativos y el destacado papel que dichos criterios desempeñan en las decisiones judiciales. Esto puede advertirse con claridad en el ordenamiento jurídico ordinario. A modo de ejemplo, cabe recordar la incorporación en el Código Civil argentino del artículo 1198 que establece, entre otras cosas, que los contratos deben celebrarse, interpretarse y ejecutarse de buena

39 Cfr. Nino, C. S., "La paradoja de la irrelevancia moral del gobierno y el valor epistemológico de la democracia", cit., p. 107. 
fe y que, en determinados tipos de contratos, si la prestación a cargo de una de las partes se tornara excesivamente onerosa, por acontecimientos extraordinarios e imprevisibles, la parte perjudicada podrá demandar la resolución del contrato. Otro ejemplo de lo recién mencionado es el artículo 7.2 del Código Civil español que establece que la ley no ampara el abuso del derecho o el ejercicio antisocial del mismo. Según este artículo,

...todo acto u omisión que por la intención de su autor, por su objeto o por las circunstancias en que se realice sobrepase manifiestamente los limites normales del ejercicio de un derecho, con daño para tercero, dará lugar a la correspondiente indemnización y a la adopción de las medidas judiciales o administrativas que impidan la persistencia en el abuso.

Lo que acaba de mencionarse con respecto al derecho ordinario, resulta todavía mucho más evidente con relación al derecho constitucional. Como ha puesto de manifiesto el llamado "neoconstitucionalismo", las Constituciones democráticas occidentales se han transformado en proclamadoras jurídicas de los valores fundamentales de la vida de la sociedad, entre los que sobresalen los derechos humanos, inviolables e inalienables. ${ }^{40} \mathrm{~A}$ modo de ejemplo, se puede mencionar la octava enmienda de la Constitución de Estados Unidos de América que establece que no se infligirán penas "crueles e inusuales". Otro ejemplo puede encontrarse en el artículo 1o. de la Constitución alemana que establece que: "La dignidad humana es inviolable. Respetarla y protegerla es obligación de todo poder público". La Constitución de Timor Oriental (promulgada pocos años atrás por uno de los últimos países en ser reconocido como independiente por la comunidad internacional) también recoge este tipo de estándares. Por ejemplo, en su artículo 34 establece la invalidez de la prueba obtenida por medio de "la violación

40 Cfr. Cruz, L. M., La Constitución como orden de valores. Problemas juridicos y políticos, Granada, Comares, 2005, passim. 
de la integridad física o moral de un individuo". ${ }^{41}$ La Constitución española establece en la primera parte de su artículo 17 que "toda persona tiene derecho a la libertad y a la seguridad". La Constitución argentina no es una excepción en este sentido. Como ejemplo, basta con nombrar su artículo 14 bis que establece que se le asegurarán al trabajador condiciones "dignas y equitativas de labor".

La consecuencia de lo mencionado con respecto al "neoconstitucionalismo" es que los contenidos materiales de la Constitución la tornan prácticamente omnipresente en todo acto de aplicación y creación de derecho, lo que exige un tipo de interpretación que necesita recurrir a valoraciones, desplazando así el protagonismo que tenía el Parlamento dentro de los poderes políticos hacia los tribunales con competencia constitucional y generando cambios en el principio de división de poderes característico del Estado de derecho tradicional. ${ }^{42}$ Todo esto sucede no sólo en los países donde se han promulgado Constituciones recientes, ya que en muchas casos lo que ha cambiado no es tanto el texto constitucional como el modo de concebir el orden que constituyen. ${ }^{43}$

El hecho de que el derecho actual normalmente haga depender la obligatoriedad o validez de sus normas de su coherencia con diferentes criterios morales debería suponer que quienes sostienen que la obligatoriedad del derecho no ha de fundarse en criterios morales porque sino el derecho sería incapaz de guiar o resultar autoritativo, también deban afirmar que el derecho actual se ha vuelto incapaz de guiar, hacer una diferencia práctica o de resultar autoritativo.

41 Sobre la constitución de Timor Oriental cfr. Etcheverry, J. B., "Building a Democracy respectful of Human Rights: the Constitutional Design that Emerges from the Philosophical Roots of the Constitution of Timor-Leste", en Binchy, W. (ed.), The Constitution of Timor-Leste, Dublin, Clarus, 2010.

42 Cfr. Alexy, R., El concepto y la validez del derecho, cit., pp. 159 y ss.

43 Cfr. Zagrebelsky, G., Il diritto mite. Logge, diritti, guistizia, Torino, Einaudi, 1992, trad. de M. Gascón. El Derecho dúctil. Ley, derechos y justicia, Madrid, Trotta, 1995, pp. 9 y ss. 
En definitiva, resulta llamativo que quienes han dedicado grandes esfuerzos por defender, como una característica del Derecho, su capacidad de obligar, guiar y su pretensión de estar dotado de autoridad, tengan que terminar admitiendo que en realidad estas características no resultan del todo aplicables, al menos y en buena medida, al derecho actual, porque este último normalmente hace depender su obligatoriedad de criterios morales.

Más aún, quienes defienden que para que el derecho pueda ser capaz de guiar o resultar autoritativo su obligatoriedad no ha de depender de la moral también han de sostener que paradójicamente el paso a la vigencia histórica de algunos derechos fundamentales que se ha propiciado en el derecho actual, lo torna irrelevante o superfluo, en vez de especialmente relevante como suele considerarse de forma generalizada.

\section{La paradoja de un derecho desprovisto de la moral}

La tercera paradoja, que se advertirá a continuación, se encuentra vinculada con las anteriores. Lo que se intenta poner de relieve es que si por supuestas exigencias de racionalidad la obligatoriedad del derecho no depende o no ha de depender de criterios morales, ya que de otro modo perdería su capacidad de guía, de hacer una diferencia práctica o de resultar autoritativo, el riesgo que se corre es que el derecho (sobre todo el actual) se vuelva paradójicamente arbitrario. 44

En este sentido, si se considera que el derecho pierde su relevancia, capacidad de guia y fuerza autoritativa por vincularse con la moral, y esto último es lo que actualmente explicitan los ordenamientos jurídicos, debe concluirse que dichos ordenamientos se han vuelto radicalmente indeterminados.

44 Ollero, A., Derecho humanos. Entre la moral y el derecho, México, UNAM, 2007, p. 259. 
Esto sería así, al punto que los ciudadanos y los funcionarios que tienen la responsabilidad de dirimir las diferentes contiendas jurídicas quedarian totalmente desprovistos de toda guía y, por lo tanto, la discrecionalidad con la que han de actuar y decidir parece tan amplia que facilita los excesos, especialmente, por parte de la autoridad. ${ }^{45}$

\section{LA RELEVANCIA DE LA DETERMINACIÓN LEGAL-JUDICIAL: UNA RESPUESTA A LA PARADOJA DE LA IRRELEVANCIA MORAL DEL DERECHO}

Hasta aquí se ha intentado poner de manifiesto algunas de las dificultades de separar radicalmente la justificación del derecho de la moral y de sostener que el derecho se vuelve irrelevante o incapaz de hacer una diferencia práctica, guiar o ser autoritativo si su obligatoriedad depende de su adecuación a algunos criterios morales (sobre todo teniendo en cuenta que en la actualidad los ordenamientos jurídicos suelen explicitar dicha dependencia).

No obstante, todavía nada se ha dicho sobre cómo superar la paradoja de la irrelevancia moral del derecho. Siguiendo a Nino, puede decirse que la paradoja de la irrelevancia moral del derecho tiene tres presupuestos: (i) que el individuo desee tomar en cuenta principios morales y actuar conforme a ellos; (ii) que sabe qué disponen esos principios, y (iii) que dichos principios siempre estipulan una única solución para cualquier situación en la que el individuo se encuentra. ${ }^{46}$

45 Cfr. Etcheverry, J. B., Objetividad y determinación del derecho. Un diálogo con los herederos de Hart, Granada, Comares, 2009, pp. 100 y ss., 112 y ss., 179.

46 Hay que reconocer que Nino advierte dos presupuestos más, que considera se encuentran en un nivel más profundo que los anteriores y que son de índole meta-ética. El primero de ellos sugiere que existe un orden moral independiente de las prácticas sociales involucradas en el derecho. El segundo supone que se puede acceder cognitivamente a ese orden moral de modo independiente a las prácticas involucradas en la existencia del derecho. $C f r$. Nino, C. S., "La paradoja de la irrelevancia moral del gobierno y el valor epistemológico de la democracia", cit., pp. 102 y ss. 
En el apartado anterior se ha intentado mostrar que no tiene mucho sentido negar los presupuestos (i) y (ii), recién mencionados, para resolver el problema planteado por la paradoja de la irrelevancia moral del derecho, porque su rechazo no supone en realidad solucionar el problema de la justificación del derecho planteado por la paradoja sino negarlo, declinando a que tenga algún tipo de sentido preguntarnos directamente por la justificación del derecho.

Además, debido a que el derecho actual suele remitir a criterios morales de validez jurídica, la negación de (i) y (ii) supone también afirmar que el derecho se ha vuelto incapaz de guiar o de ser autoritativo por resultar radicalmente indeterminado. Sin embargo, queda por establecer si pueden superarse los problemas que plantea la paradoja de la irrelevancia moral del derecho rechazando el presupuesto (iii). ${ }^{47}$

\section{La inevitable posibilidad discursiva y la relevancia del derecho}

Si la moral ideal a la que recurren los ciudadanos y funcionarios que desean justificar su obrar no siempre ofrece una única respuesta correcta para cada posible caso, la relevancia del derecho para aportar razones para la acción podria estar fundada en su capacidad de proveer soluciones

\footnotetext{
47 Hay que reconocer que existen otros intentos de superar la paradoja de la irrelevancia moral del derecho sin rechazar (iii). Entre ellos, destaca el que ha desarrollado el propio Nino al proponer que el derecho de origen democrático, al ser el mejor sucedáneo del discurso moral, posee un valor epistemológico como método de conocimiento de la moral, lo que lo vuelve capaz de poseer una "presunción de validez moral" y, por tanto, de crear razones para creer que hay razones para la acción. Cfr. Nino, C. S., "La paradoja de la irrelevancia moral del gobierno y epistemológico de la democracia", cit., pp. 97 y ss. No obstante, en esta oportunidad no abordaremos dicho intento, ni sus dificultades. Al respecto, cfr. Cianciardo, J., "La paradoja de la irrelevancia moral del gobierno y del derecho en Nino", Buenos Aires, 2010, pro-manuscrito. En un trabajo reciente, Iglesias Vila ha criticado el esfuerzo antes comentado de Nino y ha sugerido como superar sus deficiencias. $C f r$. “¿Es realmente superfluo el derecho? Justicia politica e insularidad del razonamiento jurídico", en Alegre, M., Gargarella, R. y Rosenkrantz, C. (coords.), Homenaje a Carlos S. Nino, Buenos Aires, La Ley, 2008, pp. 119-136.
} 
cuando la moral guarda silencio u otorga muchas soluciones razonables posibles para los casos. ${ }^{48}$

En este sentido, cabe recordar lo que afirma Aquino (al responder a la versión de la paradoja citada al comienzo de este trabajo) sobre la imposibilidad real de derivar siempre una única respuesta moralmente correcta o razonable de los principios morales últimos (válidos por su mérito y no justificables a su vez por otros principios), lo que, a su juicio, "hace necesario que la razón humana proceda ulteriormente a sancionar algunas leyes particulares". 49

En sintonía con esto último, algunos autores (v. g., Finnis) han ido desarrollando la idea de la "inconmensurabilidad" de cierto tipo de bienes y razones. Con esta idea se quiere poner de manifiesto que en muchas ocasiones la conducta humana pueda orientarse hacia una gran variedad de opciones igual o inconmensurablemente racionales, al menos en principio y muchas veces también en último término. Esto sería así, al menos en parte, porque no necesariamente todos los parámetros que definen como correcta

48 Un debate de algún modo vinculado con lo que se está exponiendo es el que se desata en torno a la tesis (atribuida a Dworkin) de que el Derecho siempre ofrece una única respuesta correcta. Algunos antecedentes de esta idea pueden encontrarse en Dworkin, R., Taking Rights Seriously, Londres, Duckworth, 1977, trad. de M. Guastavino, Los derechos en serio, Barcelona, Ariel, 1984, pp. 396 ss. y 455 y ss. En El imperio de la justicia varias referencias hacen alusión a esta idea. Un ejemplo en Dworkin, R., El imperio de la justicia, cit., p. 191. Existe todo un debate sobre el alcance de esta tesis y su evolución. Entre otros trabajos cfr. Bix, B., Law, Language, and Legal Determinacy, cit., pp. 77 y ss.; Coleman, J., "Truth and Objectivity in Law", cit., pp. 48 y ss.; Endicott, T., "Ronald Dworkin y las consecuencias de la vaguedad", trad. de J. J. Moreso y P. Navarro, Doxa 19, 1996 y en Palabras y reglas. Ensayos de filosofía del derecho, cit., pp. 93 y ss.; y Finnis, J., "On Reason and Authority in "Law's Empire", Law and Philosophy, 6, 1987, pp. 372 y ss. Bonorino ha publicado un libro en castellano al respecto. Cfr. Bonorino, P. R., Objetividad y verdad en el Derecho, Bogotá, Universidad Externado de Colombia, 2002. En 2006 se ha publicado un debate entre Massini y Moreno Rodríguez Alcalá sobre el alcance de esta tesis. Cfr. Massini Correas, C. I., "Dworkin, Finnis y la "única respuesta correcta"”, en Legarre, S., Miranda Montecinos, A. y Orrego, C., La lucha por el derecho natural, Santiago, Universidad de los Andes, 2006, pp. 95-117, y Moreno Rodríguez Alcalá, R., "Respuestas correctas, justas y la persistencia del encanto del legalismo. Comentario a "Dworkin, Finnis y la única respuesta correcta" del Prof. C. I. Massini C.”, en Legarre, S., Miranda Montecinos, A. y Orrego, C., La lucha por el derecho natural, cit., pp. 119-149.

49 Tomás de Aquino, Summa Theologiae, I-II q. p. 91, a. 3. 
una decisión son conmensurables. Dicho de otro modo, no parece factible obtener en todo caso una unidad común de medida entre todos los bienes y razones. ${ }^{50}$

Con una aproximación no exactamente coincidente con la de Aquino o Finnis, Alexy llega a una similar conclusión al considerar que debido a la imposibilidad de derivar una única solución para cada problema aplicando las reglas del discurso (que expresan las condiciones de la argumentación práctica racional), resultan necesarios los procedimientos jurídicamente regulados capaces de transformar la deliberación y la argumentación en una decisión y evitar que el discurso quede paralizado y, por lo tanto, no pueda operar en el plano real. 51

Resta advertir que la inevitable posibilidad discursiva, para Aquino, es producto de la limitación (imperfección) de la razón humana para participar o conocer acabadamente el orden moral. Dicha participación se daría "en cuanto a algunos principios generales, mas no en cuanto a la ordenación peculiar de cada una de las cosas singulares" (por más que esta ordenación exista). ${ }^{52}$ Para Alexy, la inevitabilidad de la posibilidad discursiva se basa en que el discurso práctico: i) no prescribe las premisas normativas de partida de los participantes en el discurso; ii) no establece todos los pasos argumentativos para alcanzar un resultado; y iii) algunas reglas, que tienen carácter ideal, sólo pueden ser cumplidas de forma aproximada, ya que en el discurso práctico real no se dan plenamente las condiciones del discurso práctico ideal (tiempo ilimitado, participación ilimitada y ausencia total de coacción en aras de producir plena claridad lingüística-conceptual, información empírica com-

50 Cfr. Raz, J., Engaging Reason. On the Theory of Value and Action, cit., pp. 46-66; y Finnis, J., "On Reason and Authority in "Law's Empire"”, cit., pp. 372-375; o, del mismo autor, "Concluding Reflections", cit., p. 238; "Natural Law and Legal Reasoning”, cit., p. 9; y Ley Natural y Derechos Naturales, cit., pp. 141 y ss.

51 Cfr. Alexy, R., "La institucionalización de la razón”, trad. de J. A. Seoane, Persona y Derecho, 43, 2000, pp. 233-235.

52 Cfr. Tomás de Aquino, Summa Theologiae, I-II q. 91, a. 3. Resulta oportuno aclarar que con esta afirmación Aquino no pretende negar la intelectualidad de la prudencia. Al respecto, por ejemplo, cfr. ibidem, II-II q. 47 a. 2- 5; y II-II q. 181 a. 2. 
pleta, aptitud y disposición plenas para el intercambio de roles y total ausencia de prejuicios). ${ }^{53}$ Como puede advertirse, al final de cuentas tanto la posición de Aquino como la de Alexy defienden la inevitable posibilidad discursiva, fundamentándola en ambos casos (entre otras cosas) en las limitaciones del ser humano al buscar respuestas por medio del razonamiento práctico. ${ }^{54}$

Al margen de los diferentes modos en que puede fundarse la idea de que la posibilidad discursiva resulta inevitable, si se acepta que pueden existir muchas opciones razonables (o moralmente correctas) para regular una misma situación de la vida social, cuando una norma jurídica regula dicha situación determinando como únicamente correcta una de las diferentes soluciones razonables, la existencia de dicha norma será relevante y capaz de coordinar la conducta de los ciudadanos por más que a la hora de decidir si ha de ser aplicada y cuál es concretamente su alcance no sólo se tenga en cuenta lo que establece, sino también otras razones $(v . g$., la corrección moral del resultado al que conlleva). Lo que quiere afirmarse aquí es que cuando muchas soluciones a un problema son razonables, las normas jurídicas positivas, al optar por una de todas estas opciones (indiferentemente) razonables, tendrían la capacidad de determinar autoritativamente cuál de todas las soluciones ra-

53 Cfr. Alexy, R., "La institucionalización de la razón”, cit., pp. 229 y 230.

54 Con respecto a esta última cuestión, resulta inevitable hacer una mención al aporte de la hermenéutica contemporánea. Las conclusiones del estudio que hace la hermenéutica de las condiciones de posibilidad de la comprensión ponen de manifiesto la dependencia reciproca entre comprensión y pre-comprensión (prejuicio) y el carácter circular del comprender. Cfr. Gadamer, H. G., Verdad y método. Fundamentos de una hermenéutica filosófica, trad. de Ana Agud Aparicio y Rafael de Agapito, Salamanca, Sígueme, 1977, passim. Estas conclusiones en buena medida pueden fundarse en las limitaciones de la capacidad del ser humano para comprender. En concreto, las limitaciones propias de un ser que conoce desde un punto de vista y que es lo que es por su inmersión en una cultura, lenguaje, tradición, junto con lo ilimitada e infinita que es su apertura a conocer. Cfr. Serna, P., "Hermenéutica y relativismo. Una aproximación desde el pensamiento de Arthur Kaufmann", en Serna, P. (dir.), De la argumentación jurídica a la hermenéutica: Revisión crítica de algunas teorías contemporáneas, 2a. ed., Granada, Comares, 2005 y Orrego, C., "Hermenéutica y no cognitivismo ético en la teoría analítica del derecho", Ars Interpretandi, 3, 1998, pp. 321-323. 
zonables es la jurídicamente obligatoria. De este modo, las normas jurídicas positivas serían capaces de proporcionar un criterio de resistencia frente a otras opciones razonables, cerrando o limitando (como sugería Shapiro) las posibilidades de obrar que resulten inconsistentes con ellas. Justamente esta capacidad que tendrian las normas jurídicas de atrincherar unos criterios razonables de obrar como los obligatorios (y separarlo de un grupo más amplio de buenas razones para obrar) es lo que les permitiría guiar de un modo especial las conductas y producir efectos prácticos. Más aun, puede decirse que la fuerza vinculante (capacidad de obligar) de las normas jurídicas no surge sólo de su razonabilidad sino también de su capacidad para añadirle a una de las diferentes soluciones razonables la capacidad de coordinar las conductas de los miembros de una comunidad. ${ }^{5}$ En palabras de Aristóteles, las leyes establecidas para casos concretos, y que no tienen en todas partes la misma fuerza, hacen que "aquello que en un principio da lo mismo que sea así o de otra manera" (v. g., que se deba sacrificar una cabra y no dos ovejas), "ya no d[é] lo mismo" y que su cumplimiento resulte debido en justicia (por su razonabilidad). En concreto, para Aristóteles, lo que establecen estas leyes es debido por un tipo de justicia "fundada en la convención y en la utilidad", en contraposición a lo que denomina la "justicia natural". 56

Por ello, es correcto afirmar que el surgimiento del derecho parece estar relacionado con su capacidad para coordinar razonablemente a los ciudadanos de un modo que no lo consigue solamente la moral. Más aún, dicha coordinación racional sería lo que permitiría a los ciudadanos desarrollarse de una manera que no lograrían si las normas jurídi-

55 Aquino sostiene algo parecido al afirmar que las leyes humanas que derivan de la ley natural como una determinación de ella, le "añaden" algo a dicha ley natural que no tiene "más fuerza que la de la ley humana". Cfr. Tomás de Aquino, Summa Theologiae, I-II q. 95, a. 2.

56 Aristóteles, Etica a Nicómaco, V, 7, 1135a (se emplea la edición bilingüe a cargo de M. Araújo y J. Marías, Madrid, Centro de Estudios Constitucionales, 1994). 
cas no existiesen o si no se tomase en serio su aplicación. ${ }^{57}$ Sin embargo, para sostener esto no es necesario desconfiar de la objetividad de los criterios morales, sino que basta con advertir que la moral es capaz de guiar las conductas en muchas direcciones posibles y válidas y que si no existiese el derecho para regular la conducta de los ciudadanos, incluso quienes estuviesen dispuestos a cumplir con lo que manda la moral, estarían sometidos a una falta de predictibilidad en la que la mayoría de los conflictos juridicos serían resueltos por elección entre alternativas abiertas. Una falta tal de predictibilidad es lo que atentaría contra la existencia de un orden que permita un tipo de coordinación que facilite la coexistencia pacifica y que asegure la autodeterminación y la libertad de los ciudadanos respecto de algunas formas de manipulación a las que puede intentar recurrir la autoridad. 58

Un par de ejemplos ayudarán a terminar de explicar este punto. Si bien es importante la organización del tránsito para que éste sea más seguro y eficiente, todas las razones que puedan considerarse al respecto no parecen decir si es más razonable que se circule en un sentido o en otro, por la derecha o la izquierda, en una carretera o calle de doble sentido. Por ello, las normas jurídicas positivas que regulan autoritativamente en qué dirección se debe circular son capaces de guiar, generar efectos y determinar una cuestión por más que a la hora de aplicarlas se tengan en cuenta criterios de razonabilidad práctica (morales) para confirmar su obligatoriedad en el caso concreto. Otro ejemplo, menos trillado que de las normas de tránsito y que también sirve para explicar la línea argumentativa que se propone, es el de las normas que determinan plazos procesales. Si bien el establecimiento de los plazos procesales por parte de estas

57 Cfr. Finnis, J., Natural Law and Natural Rights, Oxford, Clarendon Press, 1980, traducción de Orrego, C., Ley natural y derechos naturales, Buenos Aires, Abeledo Perrot, 2000, cap. IX, y Cotta, S., El derecho en la existencia humana. Principios de ontofenomenología jurídica, trad. de I. Peidró Pastor, Pamplona, EUNSA, 1987, pp. 50 y ss., 84 ss., y pp. 108-122.

58 Cfr. Finnis, J., Ley natural y derechos naturales, cit., pp. 298-304. 
normas responden a la búsqueda de celeridad en los procesos que resulte respetuosa del derecho de defensa u otros bienes, normalmente, cuando es necesario establecer dichos plazos, existen muchas posibles opciones aceptables, porque todas ellas satisfacen los bienes mencionados - celeridad y defensa-. En este sentido, parece evidente que el hecho de que el plazo para contestar una demanda civil sea de 20 o 25 días resulta una cuestión contingente que deberá resolver quien tenga la autoridad para regular tal cuestión. Esto no implica que dicho plazo podría ser de cualquier tipo, pues si es demasiado breve puede lesionar el derecho de defensa y si es demasiado largo atentar contra la celeridad procesal.

En definitiva, debido a que muchas (quizás, la gran mayoria) de las cuestiones reguladas por las normas jurídicas admiten múltiples soluciones razonables, al menos la decisión que dichas normas toman dentro de esas opciones tiene una innegable relevancia y efecto práctico, porque establecen cómo ha de resolverse una cuestión que si no estuviese regulada podría ser resuelta de muchas maneras. 59

\section{Respuestas a los distintos modos en que se presenta la paradoja de la irrelevancia moral del derecho}

De aceptarse esta línea argumentativa resta establecer en qué medida permite superar los diferentes modos en que se expresa la paradoja de la irrelevancia moral del derecho. En

59 Con respecto al alcance de la libertad de los operadores jurídicos para decidir entre alternativas inconmensurablemente satisfactorias, resulta especialmente dificil dar muchas precisiones más que las que hasta ahora se han ofrecido. El pensamiento de Finnis refleja claramente esta dificultad ya que, por un lado, afirma que: "en el área vasta donde el legislador, más que aplicar o ratificar determinados principios o reglas de razón, construye determinaciones, hay relativamente pocos puntos en los que su elección pueda ser razonablemente considerada como "sin trabas" o "arbitraria»". Sin embargo, luego termina afirmando que: "[e]s verdad que el razonamiento de quienes ejercen la autoridad frecuentemente termina sin identificar ninguna decisión como la única razonable". Cfr. Finnis, J., Ley naturaly derechos naturales, cit., pp. 313 y 316. 
este sentido, se ha explicado la visión según la cual el derecho perdería su capacidad de guía o de tener autoridad si su obligatoriedad depende de su conformidad con la moral. Como se ha dicho anteriormente, la capacidad que tiene el derecho de atrincherar unos criterios razonables como los obligatorios es lo que le permite guiar de un modo especial las conductas y producir efectos prácticos por más que su obligatoriedad en última instancia dependa de su corrección moral. Tampoco hay inconveniente en reconocerle autoridad al derecho por más que su obligatoriedad dependa de su corrección moral si se advierte que el derecho tiene la capacidad autoritativa para elegir entre diferentes posibilidades razonables de ordenar y coordinar la vida social. Así, siguiendo a Raz, se puede afirmar que el derecho, por medio de sus normas, aporta razones para la acción y para excluir el balance de razones (que de no existir el derecho sería necesario realizar). Estas afirmaciones simplemente han de ser matizadas agregando que, en realidad, las razones que aporta el derecho son sólo presuntivamente excluyentes. Lo anterior significa que las razones que ofrece el derecho en principio reemplazan a las razones de quienes están sometidos a él siempre y cuando el derecho haya optado autoritativamente por una de todas las opciones razonables o correctas. 60

La linea argumentativa que se viene desarrollando también parece capaz de explicar cómo una Constitución cuya obligatoriedad depende entre otras cosas de su corrección moral no resulta irrelevante para asignarle validez a otras normas jurídicas. En este sentido, si bien es correcto afirmar que en última instancia la obligatoriedad de las normas jurídicas infra-constitucionales no depende únicamente de que hayan sido dictadas conforme a criterios que establece la Constitución de la que derivan, dichas Constituciones siguen siendo relevantes para determinar cuáles de todos los posibles criterios formales y materiales moralmente correctos o razonables habrá que considerar a la 
hora de establecer la validez de las normas jurídicas infra-constitucionales.

Por otra parte, afirmar que el derecho tiene la capacidad de elegir entre distintas opciones razonables de ordenar (y, de este modo, coordinar) la vida social también ayuda o permite comprender el importante papel que tienen en este objetivo las normas jurídicas infra-constitucionales. Si bien la mayoría de los sistemas y prácticas constitucionales occidentales han incorporado, a través de los derechos fundamentales, criterios materiales de validez jurídica normalmente expresados como principios necesitados de una determinación creativa, esto no muestra que en la actualidad toda respuesta deba buscarse y encontrarse en la realidad constitucional y que las normas jurídicas infra-constitucionales a lo sumo serán solo redundantes (y, por lo tanto, superfluas) del contenido constitucional. Justamente el imprescindible papel de las normas infra-constitucionales será el de determinar cuál de todos los posibles modos (razonables y conformes a los contenidos materiales de la Constitución) de ordenar (y coordinar) la vida social regirá en una sociedad en concreto.

Por último, resta mencionar que la línea argumentativa que se viene desarrollando también puede ayudar a explicar la relevancia de la legitimidad de origen de las normas jurídicas, por más que se tenga en cuenta su corrección moral para establecer su obligatoriedad. Como se ha visto, debido a que la moral es capaz de guiar el obrar en varias direcciones posibles y correctas es necesario que el derecho determine de qué modo concreto ordenar y coordinar la vida social. Dicho ordenamiento comprende también la determinación de las reglas razonables por las cuales se podrá determinar la legitimidad de un gobierno. Así, vincular de algún modo la obligatoriedad de las normas jurídicas con algunos principios morales no necesariamente supone afirmar que el origen legítimo o ilegítimo de dichas normas juridicas sea irrelevante para establecer su obligatoriedad. $\mathrm{Su}$ obligatoriedad qua normas jurídicas dependerá tanto de 
la legitimidad de su origen como de su razonabilidad, justamente por la importancia que tiene que se respete todo ordenamiento jurídico razonable como herramienta de coordinación que facilita la coexistencia pacífica y que asegura la autodeterminación y la libertad frente a algunas formas de manipulación a las que puede recurrir la autoridad. ${ }^{61}$

\section{Desafios de la propuesta}

Sin embargo, la linea argumentativa que proponemos para superar la aparente paradoja de la irrelevancia moral del Derecho no está exenta de dificultades. Una primera dificultad es que, si la moral en algunos casos no ofrece razones para que un caso se resuelva de un determinado modo, entonces puede resultar dudoso que en esos casos el derecho sea moralmente relevante o tenga capacidad justificativa. Dicho de otra manera, con esta observación se cuestiona cómo puede explicarse la capacidad del derecho para fabricar o jerarquizar razones que no preexistían y que le permiten justificar su decisión. ${ }^{62}$

Al respecto hay que decir que, en realidad, esta dificultad es sólo aparente. De alguna manera ya se ha sugerido que si bien el razonamiento práctico se basa en principios en cierto modo necesarios - que van desde principios tan generales como el que establece hacer el bien y evitar el mal a otros más específicos como los que buscan evitar los resultados absurdos-, su aplicación a casos particulares resulta en muchos casos contingente. ${ }^{63}$ Ello es así no sólo porque las situaciones de hecho difieren mucho entre sí, sino también porque la conducta humana puede orientarse hacia una gran variedad de opciones igualmente racionales, al menos en principio y muchas veces también en último término. Al respecto se han referido recientemente algunos

61 Ibidem, pp. 298-304.

62 Cfr. Nino, C. S., "La paradoja de la irrelevancia moral del gobierno y epistemológico de la democracia", cit., pp. 107 y ss.

63 Cfr. Tomás de Aquino, Summa Theologiae I-II q. 94, a. 4. 
autores destacando la inconmensurabilidad de cierto tipo de bienes y razones. Por ejemplo, no parece razonable afirmar a priori (y en algunos casos en último término) que "un buen tango" es mejor que "un bello vals", o que es mejor "pasar un rato leyendo un libro" que "jugando un partido de fútbol". En estos casos, la decisión no involucra exclusivamente elementos racionales y, por ello, las decisiones no siempre se toman prescindiendo de preferencias y emociones. Sin embargo, la presencia de estos elementos de índole afectiva, emocional o volitiva no autoriza sin más a considerar estas decisiones como irracionales, ya que se adoptan entre alternativas racionales.

Por otra parte, la inconmensurabilidad de algunos bienes y razones y la contingencia de las situaciones de hecho no convierten el problema de la corrección de las acciones humanas en una cuestión indecidible, ya que la existencia de más de una respuesta correcta o buena a una cuestión, no impide que existan otras respuestas incorrectas o malas. ${ }^{64}$

En definitiva, cuando la moral ofrece varias opciones viables, el derecho no pierde capacidad justificativa si elige una de las opciones correctas, ni crea una nueva razón para justificar su opción porque dicha razón es ofrecida, en última instancia, por la moral, sino que simplemente está justificado que pueda elegir una de las opciones correctas, ya que su elección le añade a una de estas opciones la capacidad de coordinar las conductas de los miembros de una comunidad para que puedan desarrollarse de un modo que no alcanzarian sin dicha regulación.

Por último, si bien la respuesta recién ofrecida a la paradoja de la irrelevancia moral del derecho puede resultar auspiciosa hay que reconocer que también tiene que enfrentar otro desafio. En este sentido, resta todavía dilucidar

64 Cfr. Raz, J., Engaging Reason. On the Theory of Value and Action, Oxford, Oxford University Press, 1999, pp. 46-66, y Finnis, J., "On Reason and Authority in "Law's Empire", Law and Philosophy, 6, 1987, pp. 372-375; o, del mismo autor, "Concluding Reflections", Cleveland State Law Review, 38, 1990, p. 238; "Natural Law and Legal Reasoning", Cleveland State Law Review, 38, 1990, p. 9; y Ley natural y derechos naturales, cit., pp. 141 y ss. 
si es aplicable a los casos en los que están en juego cuestiones relacionadas con los derechos humanos. Dicho de otro modo, queda todavía por aclarar si cuando surgen cuestiones relativas a derechos humanos el derecho tiene capacidad de elección entre multiplicidad de soluciones todas ellas correctas, haciendo que su rol determinativo sea relevante desde el punto de vista justificatorio, o si, por el contrario, en estos casos las decisiones de los constituyentes o los legisladores, que reconocen dichos derechos, o de los tribunales, que los aplican, sólo cuentan con una sola opción moralmente aceptable $\mathrm{y}$, por lo tanto, su función en esos casos consiste únicamente en reconocer o repetir una exigencia moral ineludible asegurándose de que se la cumpla, incluso si es necesario de forma coactiva.

Para encaminarnos a responder este interrogante resulta iluminador tener en cuenta que aquellos contenidos u ordenaciones que (como dice Aristóteles) en todas partes tienen (o deberian tener) la misma fuerza, como los derechos humanos, necesitan y son formalizados y determinados por los operadores jurídicos que han de reconocerlos, aplicarlos y resolver las controversias en los que están en juego. Como es sabido, normalmente los derechos humanos son recogidos en normas abiertas, generales, amplias y necesitadas de delimitación y del llenado de la legislación y la jurisprudencia. De hecho, en general estos derechos suelen instrumentarse por medio de principios jurídicos que son por definición en alguna medida indeterminados, matizables y que no brindan consecuencias jurídicas precisas sino sólo razones prima facie, pautas que iluminan un camino pero que no ofrecen u obligan a una única decisión. Todo esto hace que resulte necesario que se advierta lo importante de la dimensión prudencial con la que han de actuar los operadores jurídicos, al intentar determinar en unas circunstancias y contextos normativos concretos el alcance de estos derechos. Esto es perfectamente compatible con el hecho de que en la práctica no sólo no exista, sino que resulte imposible, que exista una regulación legal única o una 
única interpretación judicial aceptable de dichos derechos. Por esto, que distintos tribunales adopten diferentes puntos de vista razonables sobre un problema no contradice lo que se acaba de afirmar, sino que esto puede explicarse precisamente porque la dimensión prudencial conduce a distintas soluciones y opciones legitimas. ${ }^{65}$ Con todo esto, lo que quiere ponerse de manifiesto es que incluso cuando están en juego derechos humanos, los constituyentes, los legisladores y los tribunales han de decidir cómo garantizarlos. Por más que por su carácter universal estos derechos exijan cosas que en alguna medida deberian tener la misma fuerza en cualquier parte, en muchas ocasiones su satisfacción puede ser alcanzada de diferentes modos posibles. En este sentido, Finnis afirma que no hay que concebir "como arroyos que corren por canales separados" aquellos aspectos del derecho que deberían ser iguales en cualquier parte, de aquellos otros que dan lo mismo que sean de un modo $u$ otro. 66

No obstante, en esta oportunidad simplemente advertimos el desafio que ha de ser enfrentado, esbozamos una línea de respuesta, y dejamos para otra oportunidad su desarrollo. 67

\section{Conclusiones}

Del desafio impuesto por la paradoja de la irrelevancia moral del derecho y de la respuesta esbozada en este trabajo pueden obtenerse algunas conclusiones se aspira sirvan para iluminar el camino hacia obtener algunas respuestas a las preguntas con las que iniciamos este trabajo: ¿la obligatoriedad del derecho depende de algún tipo de conformi-

65 Cfr. Serna, P. y Toller, F., La interpretación constitucional de los derechos fundamentales. Una alternativa a los conflictos de derechos, Buenos Aires, La Ley, 2000, pp. 56-60.

66 Cfr. Finnis, J., ley natural y derechos naturales, cit., p. 316.

$67 \mathrm{Al}$ respecto hay que decir que la profesora Pilar Zambrano intenta dar respuesta a esta última cuestión a partir del pensamiento de John Finnis. 
dad con la moral?; ¿es necesaria la existencia del derecho? y ¿por qué regirnos por el derecho y no, más bien, por la moral?

Como se ha visto, el derecho posee una capacidad de obligar o de dirigir normativamente la acción de sus destinatarios que no consiste meramente en enunciar exigencias o en que de hecho, muchas veces por medio de la coacción, resulta eficaz. Estas posibilidades no alcanzan para explicar por qué puedo "estar obligado" por el derecho. ${ }^{68}$ En realidad, la normatividad del derecho ha de fundarse en otras normas que le transmiten su capacidad para justificar la obligatoriedad de lo que ordena. No obstante, debido a que este proceso de fundamentación no puede continuarse al infinito, en última instancia el derecho ha de justificar la obligatoriedad de sus mandatos apelando a unas normas válidas por sus propios méritos y no justificables a su vez por otras normas. Dicho de otra manera, la normatividad del derecho sólo puede explicarse apelando en última instancia a principios morales últimos.

Por otra parte, si bien el derecho necesita que sus mandatos resulten moralmente correctos para poder justificar su obligatoriedad, esto no significa que el derecho sea completamente redundante a la moral y que, por lo tanto, no aporte nada específicamente suyo al regular la conducta de sus destinatarios. Debido a que la conducta humana puede orientarse a una gran variedad de opciones moralmente correctas, en muchas ocasiones las exigencias de la moral pueden admitir varias respuestas o soluciones correctas para una misma cuestión. Esto supone que, cuando el derecho regula una de estas cuestiones eligiendo una de las diferentes opciones moralmente correctas, la existencia del derecho aporta una determinación de las soluciones posibles que adquiere una indudable relevancia, entre otras cosas, por su capacidad para coordinar a sus destinatarios de forma que puedan desarrollarse de un modo que no alcan-

68 Dichos posibilidades quizás sí logran explicar por qué me puedo "ver obligado" por el derecho. Cfr. Hart, H. L. A., The Concept of Law, cit., p. 103. 
zarían sin dicha regulación. Así, cuando muchas soluciones a un problema son moralmente correctas, el derecho tendría la capacidad de determinar autoritativamente estas cuestiones optando entre una de las opciones razonables, proporcionando un criterio de resistencia frente a otras opciones razonables, guiando, produciendo efectos prácticos y coordinando a sus destinatarios, por más que a la hora de aplicarlo se tenga en cuenta si optó realmente por una opción moralmente correcta.

Por último, resta advertir que los intentos de explicar la normatividad del derecho como completamente autónoma a la moral que apelan a la paradoja de la irrelevancia moral del derecho para desalentar otras opciones, no sólo no logran alcanzar este objetivo ni resolver el dilema planteado por dicha paradoja, sino que además deberian terminar sosteniendo que en la actualidad el derecho no resulta capaz de guiar, obligar o resultar autoritativo, debido a que el derecho actual explicita la dependencia que su obligatoriedad tiene con respecto a algunos criterios morales. Más aún, quienes intentan esto deberian afirmar que el derecho actual se ha vuelto radicalmente indeterminado dejando una discrecionalidad tan amplia a quienes han de actuar y decidir que resulta incapaz de coordinar las acciones de los ciudadanos y que facilita los excesos, especialmente, por parte de la autoridad. 